Terakreditasi Dirjen Dikti SK No. 56/DIKTI/Kep/2005

\title{
DCA RI-Singapura: Tinjauan Negosiasi
}

\author{
Yusuf Hamdan
}

\section{ABSTRACT}

Planning is a crucial stage which could determine and leverage activities' success. There are many approach to build a plan to implement activities. This article explores BATNA Methods (Best Alternative to Negotiate Agreement) as an approach based on negotiation plan.

Providing the Case of Indonesian-Singapore Defense Cooperation Agreement as case being studied, it was concluded that the lack of BATNA has contribute a loss for Indonesia.

More concessions were given to Singapore by Indonesian in that agreement, and caused a potential disadvantage for RI government.

Kata kunci: Defense Cooperation Agreement (DCA), BATNA Methods, negosiasi

\section{Pendahuluan}

Sejak reformasi 1998, performa diplomasi Indonesia memperlihatkan penurunan. Perundingan mengenai sengketa wilayah antara Indonesia dengan berbagai pihak berujung pada lepasnya wilayah tersebut dari tangan Indonesia.

Perundingan mengenai propinsi Timor-Timur membuahkan referendum yang berujung pada lepasnya provinsi itu. Peristiwa ini dianggap sepagai tindakan politik yang salah langkah sebagai bentuk kegagalan diplomasi Indonesia (lihat Gani dalam Sudrajat, 2003:62). Sengketa pulau Sipadan dan Ligitan antara Indonesia dengan Malaysia menghasilkan kesepakatan untuk membawa sengketa ke Mahkamah Internasional yang berakhir pada lepasnya kedua pulau dari pangkuan Indonesia dan berpindah ke Malaysia. Perundingan pemerintah Indonesia dengan GAM (Gerakan Aceh Merdeka) menelurkan kesepakatan yang menyebabkan penyelesaian masa depan Aceh harus melibatkan GAM dan Masyarakat
Ekonomi Eropa (MEE).

Dalam jangka pendek, kesulitan mulai timbul saat pimpinan GAM terpilih dalam Pemilu lokal sebagai Gubernur Aceh yang mempermalukan seluruh kekuatan politik Indonesia, baik kekuatan politik Islam seperti PPP yang selama ini pengaruhnya cukup kuat di Aceh, maupun nasionalis.

Baru-baru ini, perundingan bidang pertahanan antara pemerintah Indonesia dengan Singapura menghasilkan kesepakatan yang menyulut kontroversi luas pada khalayak politik Indonesia. Bahkan, sebagian kalangan DPR RI mengancam tidak akan meratifikasi hasil perundingan. Masalah utama yang disorot adalah konsesi yang diberikan pemerintah Indonesia dianggap melampaui kewajaran, yaitu berupa pemberian wewenang kepada pihak Singapura untuk melakukan latihan perang di wilayah Indonesia dengan melibatkan pihak ketiga meskipun dengan sepengatuhan Indonesia. 
Transisi politik Indonesia pasca-Orde Baru telah membawa pergeseran yang cukup berarti dalam kehidupan sosial, politik, ekonomi, budaya, dan juga media. Dalam proses transisi politik yang labil, berbagai gejolak sosial politik di tingkat nasional maupun lokal bermunculan sejalan dengan proses konsolidasi politik yang belum tuntas sepenuhnya. Pasca gerakan reformasi, Indonesia berada dalam masa yang labil, sebab sistem lama yang otoriter telah kehilangan legitimasi dan basis moralnya, sedangkan konsensus mengenai sistem politik (demokrasi) yang baru belum berhasil dibuat. Periode ini penting untuk diperhatikan karena arah pergerakannya yang tidak menentu (lihat Denny J.A., 1999:32-39).

Dalam situasi demikian, para politisi dan negarawan semestinya sudah menyadari bahwa segala produk politik yang dibuat, termasuk perjanjian dengan negara lain, dapat berimplikasi sangat luas, sehingga dapat merugikan bangsa dalam jangka pendek maupun jangka panjang. Kita sering dikejutkan dengan dampak yang demikian cepat pasca-kesepakatan dibuat. Merdekanya Timor Timur, terpilihnya Gubernur Aceh dari mantan GAM, dan lepasnya beberapa pulau menjadi kasus-kasus besar dan tak dapat dilupakan dari catatan diplomasi dan negosiasi politik pascareformasi.

Mengenai Defence Cooperation Agreement (DCA) RI-Singapura, telah lahir sejumlah kritik dari berbagai pihak yang mengkritisi perjanjian itu. Yusron Ihza ${ }^{1}$, seorang anggota DPR-RI Komisi I yang membidangi Pertahanan, berpendapat bahwa perjanjian itu diliputi oleh misteri karena konsesi yang diberikan Indonesia kepada Singapura untuk menggunakan bagian tententu wilayahnya digunakan latihan perang oleh Singapura. Bagi Ihza, perjanjian ini memperlihatkan bahwa Indonesia tidak melihat Singapura sebagai ancaman, bahkan memberi fasilitas yang memungkinkan Singapura semakin kuat secara militer. Ihza juga mengkritik argumen yang dikemukakan Menteri Pertahanan Juwono Sudarsono yang menjelaskan bahwa dalam kesepakatan itu "ruang ditukar dengan uang", sehubungan dengan DCA dikaitkan dengan kesepakatan Ri-Singapura untuk mengekstradisi para koruptor yang lari dari Indonesia ke Singapura. Ihza mengatakan bahwa pernyataan Menhan tidak tepat karena sulitnya memperoleh kembali uang hasil korupsi dari para koruptor, sehingga yang lebih tepat dikatakan sebagai "ruang ditukar dengan barang". Bagi Ihza, motif Singapura membangun sistem Pertahanan yang melebihi keperluannya dan sikap pemerintah RI yang melakukan kalkulasi-kalkuasi tidak cermat membuat DCA diliputi oleh suatu misteri.

Siswono Yudohusodo berpendapat bahwa DCA RI-Singapura tidak lazim dalam kerja sama militer biasa karena apa yang dituangkan dalam perjanjian itu lebih mirip dengan pakta pertahanan². Argumen yang dikemukakan Yudo Husodo karena Indonesia memberikan izin sebagian wilayah RI di darat, laut, dan udara, sebagai tempat latihan militer Singapura secara permananen, sesuatu yang belum pernah dilakukan Indonesia sebelumnya dengan negara mana pun. Ia juga berpendapat, Singapura tidak memiliki keperluan yang nyata untuk memperkuat pertahanannya demikian rupa karena negara itu hanya bertetangga dengan Malaysia dan Indonesia.

Kekhawatiran lain dikemukakan oleh Wirasmo Wiroto mengenai DCA, karena dalam perjanjian tersebut Singapura diberi hak untuk melakukan latihan dengan militer negara lain setelah mendapat izin dari Indonesia ${ }^{3}$. Hak yang diberikan kepada Singapura mengundang militer negara lain untuk dapat latihan militer bersama dipandang oleh para pengkritik sebagai mengancam kedaulatan negara.

Beberapa analisis dan pandangan yang dikutip di atas merupakan sebagian wacana yang saat ini berkembang menanggapi DCA RiSingapura yang pada umumnya menyebut pemerintah RI terburu-buru menandatanganinya sebelum mempelajarinya dengan seksama.

Tulisan ini bermaksud menganalisis mengenai dibuatnya Defense Cooperation Agreement (DCA) antara pemerintah RI dengan Singapura dilihat dari sudut pandangan negosiasi, khususnya dari teori tentang BATNA (Best Alternative to Negotiated Agreement), sebuah teori negosiasi tentang bagaimana merencanakan negosiasi yang berhasil untuk mencapai kesepakatan terbaik dan 
menghindarkan terjadinya kesepakatan yang merugikan pihak kita yang melakukan negosiasi. Berdasarkan latar belakang tersebut dapat dirumuskan permasalahan yang menjadi pokok bahasan tulisan ini adalah, "bagaimana DCA pemerintah RI dengan Singapura jika dilihat dari sudut pandang negosiasi, khususnya dari teori BATNA?”

\section{Tinjauan Teori}

Menyelenggarakan kegiatan yang baik tidak dapat dilepaskan dari perencanaan. Karena perencanaan merupakan sarana untuk mengatur sebelum peristiwa berlangsung. Perencanaan yang menghubungkan keadaan masa kini dan masa yang akan datang. Seperti kata pakar manajemen, "planning bridges the gap from where we are to where we want to go"'(Koontz dan Weihrich, 1988:58).

Demikian pula yang terjadi dalam proses negosiasi. Agar negosiasi yang dijalankan berlangsung dengan baik dan berhasil sesuai dengan keinginan, seorang negosiator harus membuat perencanaan negosiasi dengan baik. Salah satu yang dapat direncanakan dengan baik adalah BATNA (Best Alternative to Negotiated Agreement.)

BATNA adalah rencana negosiasi tentang beberapa alternatif yang dapat ditempuh oleh negosiator untuk membuat atau tidak membuat kesepakatan dengan pihak lain berdasarkan tujuan negosiasi yang ingin dicapai (lihat Kennedy,1993:35). BATNA memberikan beberapa bukan satu alternatif kesepakatan yang mungkin dibuat sekalian dengan berbagai alternatif untuk ke luar dari kesepakatan jika persetujuan tidak mungkin dibuat.

BATNA memberikan gambaran mengenai wilayah-wilayah yang aman dan dapat dinegosiasikan dan wilayah-wilayah berbahaya yang sama sekali tidak dapat disentuh dan dinegosiasikan. BATNA memberikan kriteria daerah penolakan ketika seorang negosiator tidak dapat lagi melakukan tawar-menawar demi alasan apa pun.

Memahami BATNA lebih mudah dengan ilustrasi yang dapat menggambarkan kegiatan tawar-menawar dua pihak yang bernegosiasi. Dalam ilustrasi negosiasi, seorang negosiator harus menetapkan lebih dahulu tujuan dan sasaran negosiasi yang jelas, sehingga berdasarkan itu negosiator dapat membuat suatu rancangan berbagai alternatif kesepakatan yang dapat dibuatnya dengan pihak lain.

BATNA akan memuat nilai minimal yang boleh disepakati yang dikenal dengan reservation value atau walk point. WP (walk point) memberi satu garis pemisah yang menentukan wilayah aman kepada negosiator untuk melakukan kesepakatan dan wilayah yang melarangnya untuk melakukan persetujuan dengan alasan apa pun.

BATNA juga memberikan gambaran mengenai nilai tertinggi yang mungkin disepati dengan pihak lain. Nilai tertinggi yang dapat diraih dalam suatu negosiasi disebut dengan target. Negosiator tidak jarang memeroleh momentum untuk menghasilkan kesepakatan yang paling menguntungkan. Suasana negosiasi memberikan banyak peluang untuk memperoleh berbagai keuntungan yang prospektif. Peluang-peluang untuk menghasilkan keuntungan yang tercipta karena faktor eksternal, akan berubah menjadi keuntungan yang nyata apabila secara internal negosiator dapat mengubahnya menjadi keuntungan yang nyata.

Target memadukan kesempatan yang baik yang tercipta secara eksternal, dan kepandaian negosiator untuk merancang berbagai rencana kesepakatan yang memberikan keuntungan maksimal kepadanya. Selain itu, target yang ingin dicapai menggambarkan aspirasi negosiator, apakah termasuk ke dalam pembuat kesepakatan yang beraspirasi tinggi atau rendah.

Nilai tinggi atau rendah (namun masih dalam wilayah kesepatan yang boleh dilakukan) akan diolah dalam tawaran negosiator kepada pihak lain. Gambaran tawaran yang nilainya tinggi atau rendah jika dibandingkan dengan tujuan yang akan dicapai hanya boleh diketahui oleh negosiator dan bersifat rahasia tidak untuk diketahui pihak lain. Nilai tawaran yang dipublikasikan kepada pihak lain berupa tawaran pertama (opening offer) ketika masing-masing pihak diminta untuk menyatakan 
posisinya tentang suatu masalah yang akan dinegosiasikan. ${ }^{4}$

Tawaran pertama yang baik tidak boleh lebih kecil dari nilai yang akan diperoleh dalam target. Seni penawaran ini sesuai dengan taktik negosiasi elementer yang mengajarkan kepada para negosiator "mintalah lebih banyak dari yang Anda harapkan". Dengan demikian negosiator memiliki kemungkinan memperoleh hasil maksimal (Dawson, 2002:5).

Sebaliknya apabila negosiator sejak tawaran pertama tidak berani meminta lebih banyak dari yang ingin dicapainya dengan memilih membuat penawaran pembuka yang dekat dengan reservation value, maka sejak awal negosiator telah membuang peluang memeroleh hasil maksimal, kondisi buruk dapat saja terjadi sehingga untuk memperoleh nilai dalam walk point saja sulit, bahkan situasi negosiasi dapat berkembang lebih buruk lagi karena pihak lain memeroleh angin untuk menekannya sehingga kalau tidak segera disadarinya negosiator mungkin saja terpaksa membuat kesepakatan yang merugikan karena telah melanggar BATNA-nya sendiri.

Sebagai contoh, seorang yang ingin menjual rumah karena suatu kebutuhan, dia harus menetapkan lebih dahulu apa tujuannya menjual rumah. Umpamanya, dia hanya punya satu aspirasi yang mendorongnya mau menjual rumah yaitu secepatnya memperoleh uang paling tidak Rp. 500 juta.

Dengan tujuan yang sangat jelas dia dapat segera membuat BATNA. Batasan paling krusial dalam menetapkan harga rumah adalah dia boleh membuat kesepatan harga rumah berapa pun, kecuali di bawah Rp 500 juta. Setiap nilai di atasnya dapat diterima sebagai kesepakatan, tetapi yang di bawahnya, berapa pun harganya, merupakan alternatif-alternatif yang harus ditolak.

Dalam praktik, negosiasi tidak sesederhana itu. Banyak faktor yang harus menjadi pertimbangan negosiator, apalagi kalau masalah yang dinegosiasikan tidak dapat dinilai dengan uang. Pengalaman menangani berbagai kasus negosiasi yang beraneka ragam, di samping wawasan negosiator yang luas tentang negosiasi, akan membantunya sampai pada kesepakatan yang menguntungkan dirinya dan orang lain yang bernegosiasi dengannya.

Dalam negosiasi politik, konsesi-konsesi yang dipertukarkan pertama-tama bukanlah uang (kendatipun tidak dapat disangkal ada fenomena politik uang), melainkan jabatan-jabatan politik dan dukungan politik. Karena ukurannya yang kurang kuantitatif, pengingkaran atau pembelokan makna dari yang disetujui sering terjadi. Oleh sebab itu, kewaspadaan yang tinggi diperlukan agar negosiator tidak mudah terjebak dalam pembuatan kesepakatan yang merugikan.

Menurut Mills (2005:14-15), sebelum negosiasi dilakukan, negosiator perlu merencanakan BATNAnya terlebih dahulu, sehingga dengan itu ditemukan beberapa alternatif terbaik jalan menuju kesepakatan dan ditemukan pula jalan keluar apabila kesepakatan tidak dapat dicapai. Menurut Mills, BATNA yang kuat akan meningkatkan percaya diri dan kekuatan negosiator. Mills menyarankan kepada negosiator selain harus memiliki BATNA yang kuat juga harus memahami BATNA pihak lain. Dengan pemahaman itu, akan meningkatkan peluang untuk mencapai kesepakatan.

Menurut Fisher et al. (1999:115-126), BATNA yang baik juga akan meningkatkan kekuatan negosiator dalam suatu negosiasi, karena dengan BATNA yang baik, seorang negosiator tahu kekuatan dan kelemahannya, kapan harus melakukan kesepakatan dan kapan harus meninggalkan meja perundingan.

Menurut Fisher dan kawan-kawan, BATNA dapat dikembangkan dengan tiga langkah atau tindakan: (1) mendaftarkan tindakan yang dapat dilakukan untuk memeroleh persetujuan; (2) mengembangkan berbagai ide dan mengubahnya menjadi alternatif-alternatif yang praktis; (3) dan menyeleksi alternatif yang paling baik untuk mencapai atau tidak mencapai kesepakatan. Negosiator yang baik tidak akan terobsesi untuk selalu menghasilkan kesepakatan dalam setiap negosiasi yang mereka lakukan, melainkan mereka akan berpegang kepada BATNA yang telah dikembangkan dan akan selalu mengukur langkahlangkah yang telah dibuatnya dari BATNA. 


\section{Pembahasan}

Pemerintah Indonesia telah menandatangani kesepakatan kerjasama dalam bidang pertahanan (Defence Cooperation Aggreement - DCA) dengan pemerintah Singapura. Dari sudut pandang Indonesia, perjanjian ini akan berlaku efektif apabila diratifikasi oleh DPR-RI. Pada level pemerintah sendiri dijelaskan bahwa kesepakatan ini baru dapat berjalan apabila pemerintah telah membuat petunjuk teknis implementasinya. Di seberang sana, pemerintah Singapura berpandangan, DCA tidak memerlukan pengaturan lagi untuk diimplementasikan karena sifat perjanjian itu telah mengatur segi teknis pelaksanaannya.

Kesepakatan ini terus mendapat sorotan dari berbagai kalangan sejak dikemukakan ke publik sampai saat tulisan ini dibuat karena dipandang mengandung beberapa kelemahan yang merugikan Indonesia. Supaya tidak mengulang berbagai kritik yang telah dikemukakan oleh berbagai pihak, pembahasan dalam tulisan ini difokuskan kepada dimensi negosiasi dari perundingan yang dilihat dari perlunya tim negosiasi memiliki BATNA sebagai rencana negosiasi. Agar mudah melakukan analisis pembahasan mengikuti masalah yang dinegosiasikan.

Dalam perundingan pemerintah Indonesia dan pemerintah Singapura, disepakati beberapa hal antara lain:

(1) Pemerintah Indonesia sepakat dengan Singapura mengaitkan perjanjian tentang ekstradisi (yang oleh pihak Indonesia diharapkan dapat mengembalikan dana yang dikuasai para koruptor yang sebagian melarikan diri ke Singapura) dengan DCA.

(2) Pemerintah Indonesia sepakat dengan Singapura untuk memberikan izin beberapa wilayah di Indonesia untuk digunakan sebagai daerah latihan militer Singapura. Dalam pengaturan daerah latihan militer ini, militer Singapura dapat melibatkan militer negara lain setelah memperoleh izin dari pemerintah Indonesia.

Pengaitan perjanjian ekstradisi dengan DCA merupakan satu perjanjian yang seolah memberikan satu solusi menang-menang (win-win solution) dengan harapan Singapura mengembalikan dana-dana milik Indonesia dengan memulangkan para koruptor Indonesia yang bersembunyi di Singapura. Sebagai imbalannya, Indonesia memberikan ruang latihan militer bagi Singapura yang tidak memiliki lahan cukup untuk keperluan itu.

Namun dalam hal ini, sebagaimana telah diungkapkan olep para pengkritik, izin dari pemerintah Indonesia kepada militer Singapura untuk menggunakan laut, darat, dan udara Indonesia di wilayah tertentu merupakan konsesi yang nyata dan dapat langsung digunakan Singapura untuk keperluan latihan militer. Sebaliknya, perjanjian ekstradisi yang diharapkan dapat mengembalikan dana yang cukup besar yang dikorup oleh para kriminal dan sebagian melarikan diri ke Singapura merupakan satu konsesi yang dapat berujud sebagai 'pepesan kosong'. Meskipun ada dugaan sejumlah koruptor Indonesia bersembunyi di Singapura, tidak ada jaminan ketika mereka akan diekstradisi masih akan berada di sana. Mereka juga belum tentu dapat benarbenar dibawa ke Indonesia untuk diadili. Kalau pun mereka dapat diadili, tidak ada jaminan uang mereka korup masih berada di tangan mereka.

Sedangkan konsesi dari Indonesia kepada pihak Singapura begitu nyata dan sangat Signifikan. Indonesia memberikan izin kepada pihak Singapura untuk menggunakan beberapa wilayah di pulau Sumatra untuk digunakan sebagai daerah militer Singapura yang berjangka waktu cukup lama. Bahkan, salah seorang pengamat mengatakan, dengan konsesi yang diberikan Indonesia Singapura akan dapat semakin mengontrol lalu lintas perdagangan di Selat Malaka.

Dari sudut negosiasi, performa tim negosiator Indonesia memberi kesan bahwa mereka tidak memiliki BATNA yang jelas. BATNA yang mereka gunakan tidak dapat mendefinisikan keadaan secara akurat sehingga tidak dapat disusun strategi pemberian konsesi yang memadai.

Lebih buruk lagi, apabila keadaan ini terjadi justru karena pemerintah Indonesia tidak memiliki BATNA sama sekali, sehingga tidak dapat 
diketahui apa saja yang boleh dan tidak boleh dinegosiasikan oleh tim negosiasi Indonesia. Menurut Fischer, kekalahan yang dialami tim negosiasi umumnya diawali oleh ketiadaan rencana yang jelas mengenai apa yang akan dilakukan. Apa yang ingin diperoleh dan dengan apa dicapainya.

\section{Kesimpulan}

Pemikiran dalam artikel ini dapat disimpulkan sebagai berikut:

(1) Negosiasi yang baik harus diawali dengan rencana negosiasi yang baik pula. Salah satu yang dapat disiapkan adalah merumuskan BATNA sebelum negosiasi dimulai sebagai bagian dari persiapan negosiasi.

(2) Perjanjian yang dibuat oleh pemerintah Indonesia dengan Singapura tentang pertahanan yang dikenal dengan DCA seharusnya didasarkan pada BATNA yang didasarkan pada kebijakan politik Indonesia dalam bidang pertahanan yang menjunjung kedaulatan RI. Pemberian konsesi dari pemerintah Indonesia kepada pemerintah Singapura untuk menggunakan beberapa wilayah Indonesia secara relatif permanen berpotensi mengganggu kedaulatan Indonesia. Konsesi itu melampaui batas yang seharusnya telah ditetapkan sejak semula tentang apa yang boleh dan tidak boleh dinegosiasikan. DCA yang telah disepakati pemerintah RI dan Singapura, memperlihatkan berbagai kelemahan yang memungkin salah satu di antara dua hal telah terjadi. Pertama, Indonesia sama sekali tidak memiliki BATNA sebelum perundingan dimulai, sehingga tim negosiator tidak tahu batasan mana yang boleh dan tidak boleh. Kedua, tim negosiator pemerintah RI mempunyai BATNA yang jelas tetapi karena hal tertentu terpaksa dilanggar. Jika hal kedua terjadi perlu dilakukan penyelidikan mengapa hal itu dapat terjadi dan kekuatan apa yang mampu mengarahkan tim negosiasi sehingga melanggar BATNA yang telah ditetapkan.

\section{Catatan Akhir}

${ }^{1}$ Ihza, Yusron. 2007. "Kerjasama Pertahanan, Misteri DCA Indonesia-Singapura”. Kompas, 16 Agustus.

2 Yudo Husodo, Siswono. 2007. "Kerjasama Militer, Pengamanan Kedaultan Negara”. Kompas, 10 Agustus

${ }^{3}$ Wiroto, Wirasmo. 2007. "Latihan Bersama RI-Rusia, Mengapa Tidak? Sinar Harapan, 24 Agustus.

${ }^{4}$ Fischer, Gregory. "Distributive Negotiation". Tanpa Tahun. $<$ http://fuqua.duke.edu/faculty/alpha/fischer.htm

\section{Daftar Pustaka}

Dawson, Roger. 2002. Secrets of Power Negotiating : Rahasia Sukses Seorang Negosiator Ulung. Jakarta: Gramedia Pustaka Utama.

Denny JA. 1999. Jatuhnya Soeharto dan Transisi ke Demokrasi. Jakarta: Jayabaya University Press.

Fisher, Roger, et al. 2000. Getting to Yes, Teknik Berunding Menuju Kesepakatan tanpa Memaksakan Kehendak. Jakarta : Yayasan Obor Indonesia.

Fischer, Gregory. Tanpa Tahun. Distributive Negotiation. < Http://www.fuqua.duke.edu/faculty/ alpha/fischer/htm.

Gani, Abdul Salam. 2003. "Nostalgia Timor Timur". Dalam Dinamika Diplomasi Indonesia Dalam Praktik. Herman Sudrajat (ed.). Bekasi : Megapoin.

Ihza, Yusron. 2007. "Kerjasama Pertahanan, Misteri DCA Indonesia-Singapura”. Kompas, 16 Agustus.

Kennedy, Gavin. 1993. Negosiator. Jakarta: PT. Elex Media Komputindo.

Koontz dan Weichrich. 1988. Management. New York: McGrawHill. 
Mills, Harry. 2005. The Streetsmart Negotiator: Tip dan Trik Menyiasati dan Mengatasi Pesaing. Jakarta: PT. Buana Ilmu Populer.

Wiroto, Wirasmo. 2007. "Latihan Bersama RIRusia, Mengapa Tidak? Sinar Harapan, 24 Agustus.
Yudo Husodo, Siswono. 2007. "Kerjasama Militer, Pengamanan Kedaulatan Negara”. Kompas, 10 Agustus. 
